Published in final edited form as:

JAMA Pediatr. 2015 June ; 169(6): 519-520. doi:10.1001/jamapediatrics.2015.0272.

\title{
In the Aftermath of the National Children's Study
}

\author{
James M. Perrin, MD, FAAP [Professor], \\ Pediatrics, Harvard Medical School, John C. Robinson Professor of Pediatrics, MassGeneral \\ Hospital for Children, 100 Cambridge Street, \#1542, Boston, MA 02114, 617-726-8716, \\ jperrin@mgh.harvard.edu
}

Sarosh P. Batlivala, MD, FAAP [Assistant Professor], and

Pediatric Cardiology, The Children's Heart Center, Blair E. Batson Hospital for Children, University of Mississippi Medical Center, 2500 N. State Street, Jackson, MS 39216, Office: 601-984-5250, Fax:601-984-5283, sbatlivala@umc.edu

\section{Tina L. Cheng, MD, MPH, FAAP [Professor]}

Pediatrics and Public Health, Vice-Chair, Department of Pediatrics, Chair, Department of Pediatrics Johns Hopkins Bayview Medical Center, Division Chief, General Pediatrics \& Adolescent Medicine, Johns Hopkins University, 200 N. Wolfe Street, \#2055, Baltimore, MD 21287, 410614 3862, tcheng2@jhmi.edu

The Golden Globe Best Picture winner, Boyhood, illustrates the power and impact of a longitudinal study of early exposures on child and family development and future health and wellbeing. The Child Health Act (CHA) of 2000 recognized the need for such research and supported a large longitudinal study called the National Children's Study (NCS). The overarching goal of the NCS was to better understand how childhood environmental exposures impacted growth and development. Unfortunately the study never fully launched, and the NIH decided in December 2014 to "orderly close" the endeavor, marking a tremendous missed opportunity. ${ }^{1}$

The NCS was to take a life-course perspective examining links among prenatal, child, adolescent and adult health. The specific aims were "to conduct a national longitudinal study of environmental influences (including physical, chemical, biological, and psychosocial) on children's health and development." Key provisions were to 1) develop a prospective cohort study from birth to adulthood to evaluate both chronic and intermittent exposures on child health and development with consideration of prenatal exposures; 2) investigate basic mechanisms of developmental disorders and study both risk and protective factors that influence outcomes; and 3) gather data on influences and outcomes on diverse populations of children and consider health disparities among children.

Despite advances in child health, disparities by race, ethnicity, and socioeconomic status remain persistent and pervasive. Low-income and minority American children have poorer health status, morbidity and mortality compared to their more affluent and majority peers. ${ }^{2,3}$ More than $40 \%$ of children continue to live in low income households $(<200 \%$ federal poverty level). Increasing evidence supports the critical nature of early life experiences positive and negative - on children's growth and development, and epigenetic studies 
document effects on developing neuroanatomy and endocrine function, accompanying recognition of family and community factors in health and development.

US children and youth have also experienced rapid and dramatic growth in chronic health conditions over the past few decades, with over a $400 \%$ increase in activity-limiting chronic conditions since $1960.4,5$ Much growth has taken place among four major condition groups - asthma, obesity, mental health (including ADHD, depression and anxiety), and neurodevelopment (including autism). Causes of this rapid growth likely reflect genetic predisposition interacting with changes in the physical and social environments. Although new methodology allows discovery of the reasons for some growth, a careful, well-designed longitudinal study, including perinatal data, would go a long way toward answering questions about increases in chronic conditions along with study of diverse populations with a focus on health disparities. These CHA emphasis areas continue to be urgent needs.

A prospective longitudinal study design is a powerful strategy for assessing the incidence and natural history of conditions and their possible causes. A comprehensive study that measures multiple exposures, risk and protective factors (including genetic and other biomarkers), and outcomes over time offers great potential to further our understanding of health and disease. This is especially true as many diseases with significant public health impact-hypertension, diabetes - take years to develop and progress relatively slowly. Yet strong evidence notes the tracking of early childhood health to serious long-term adult disease. $^{6}$

Despite the termination of the NCS, the current NIH appropriations act (Public Law 113235) makes $\$ 165$ million available in fiscal year 2015 for the NCS "or research related to the Study's goals and mission." It is critical that remaining funds after close out of the NCS be re-directed to child health research fully consistent with the goals of the CHA. The working group advising the NIH on the future of the NCS proposed a trans-NIH approach to achieving the CHA goals and offered consideration of smaller focused studies, multi-center collaboratives, and a longitudinal cohort for biospecimens ${ }^{7}$. The need for a longitudinal cohort spanning these strategies seems clear. In this new era of "big data," NIH leaders could potentially engage partners through PCORI, AHRQ, and CDC to maximize data systems to achieve the initial aims of NCS.

Historically, investment in child health research has paid off in lives saved. The campaign on "Seven Great Achievements in Pediatric Research in the Past 40 Years" 8 highlights disease prevention by life-saving immunizations, saving premature babies by helping them breathe, reducing sudden infant death with "back to sleep", curing childhood cancers, increasing life expectancy for children with chronic diseases like cystic fibrosis and sickle cell anemia, preventing HIV maternal transmission, and saving lives with car seats and seat belts. Research investment in these seven areas has made children healthier and safer today and able to grow to healthy adulthood. Investment in child health also pays off in later adult health.

Continued scientific advancement requires a healthy pipeline of young investigators. Recent trends, including a decline in the share of research grants awarded to young investigators 
and a rise in the age at which investigators receive their first funding, pose threats to the future of the biomedical workforce ${ }^{9}$. Nevertheless, the young investigators of today will become the lead investigators of tomorrow. And new minds bring new ideas. We therefore must support and involve young investigators in this important field of study.

The NCS and "Boyhood" were conceived around the same time with the shared goal of longitudinal study. Hollywood succeeded to critical acclaim. Unfortunately, the NCS did not. Its closure, after 14 years of planning, highlights the importance of the original aims. Child health must be a priority to ensure the future wellbeing of our world, with recognition that young investigators will play a key role in our new discoveries. We strongly urge leaders to address the key underlying questions of the CHA with strong and effective investments in child health research.

\section{References}

1. NIH Director Statement on the National Children's Study. [accessed 12/12/14] http://www.nih.gov/ about/director/12122014_statement_ACD.htm

2. Cheng TL, Dreyer BP, Jenkins RR. Introduction: Child health disparities and health literacy. Pediatrics. 2009; 124(suppl3):161-162.

3. Flores G. American Academy of Pediatrics Committee on Pediatric Research. Racial and Ethnic Disparities in the Health and Health Care of Children. Pediatrics. 2010; 125(4):e979-e1020. [PubMed: 20351000]

4. Halfon N, Houtrow A, Larson K, Newacheck PW. The changing landscape of disability in childhood. Future of Children. 2012; 22(1):13-42. [PubMed: 22550684]

5. Perrin JM, Anderson LE, Van Cleave J. The rise of chronic conditions among infants, children, and youth can be met with continued health system innovations. Health Affairs. 2014; 33:2106-2115. [PubMed: 25489028]

6. Marmot, M.; Wilkinson, RG., editors. Social Determinants of Health. 2nd Edn.. Oxford University Press; 2005.

7. [accessed 1/11/15] The National Children's Study Working Group Final Report. 2014 Dec 12. http://acd.od.nih.gov/reports/NCS_WG_FINAL_REPORT.pdf

8. American Academy of Pediatrics. Seven Great Achievements in Pediatric Research in the Past 40 years. 2014 http://www.aap.org/en-us/advocacy-and-policy/federal-advocacy/Documents/ 7\%20Great\%20Achievements\%20in\%20Pediatric\%20Research.pdf.

9. Daniels RJ. A generation at risk: young investigators and the future of the biomedical workforce. PNAS. 2015 www.pnas.org/cgi/doi/10.1073/pnas.1418761112 ahead of print. 